\title{
Marketing Trends using Latest Technology
}

\author{
P.Nivetha, S.Sudhamathi
}

\begin{abstract}
Marketing deals with examing besides maintenance of the deal of return. It is the business mechanism of organizing deal and achieve the needs of clients. It is one of the best phase of company leadership along with the concern on the needs of the clients. Because of cost effectiveness and broader range, online marketing is considered as one of the effective marketing strategies in business. Over a period of timeseveral online marketing techniques have been changed. Result of changing in digital trends, marketers ought to be aware of the modifications to adapt with the trending technologies and to remain ahead in the market. These will guide them gain a competitive edge and comes out with a new methods to improve their businesses, attain leads and improve the relationship with their vital clients. Artificial intelligence and machine learning are developing aspect of numerous sectors, including marketing. Artificial Intelligence (AI) Marketing Applications offers techniques to connect performance as well as science data. Screening and analyzing huge data was once tough to achievablebut it iseasy to achieve now. This paper sheds light on the survey of AIA's possibilities for human as well as its importance in this field. This paper explores AIA as an individual contributor in the world's digital marketing.
\end{abstract}

Keywords : Online Marketing,Marketing 6.0, Digital Marketing, Trends in marketing, Artificial Intelligence Applications, AIA, Intelligent Agents.

\section{INTRODUCTION}

Artificial Intelligence(AI), just made a leap from its past adorable projection of scientific imaginative creation to the present emerging reality within a frame of technology, which can disrupt industries. In a cut-throat business environment, the function of marketing is not an exception to the concern of AI. Further, in the current study of PwC, nearly three - fourth $(72 \%)$ of marketers are interviewed and they termed AI as "Business Advantage".Artificial Intelligence Applications (AIA) are making the direction for different markets. Vast information and its unique qualities are its advantages, like:

1.Rational thoughts and behavior,

2.decision making in tough times,

3.least errors in techniques,

4. 24X7 working ability even in abnormal situations. 5.Result (cause effect) rate,

6.Low rate, asset while contrasting with the value of human , 7. Above mentioned are its current development. Through this, AI it is easy to examine environment and steps will taken to promote the gain in high economic way. Informatics, deals with the subject of intelligent agents like, system, robots ,etc,. AI can be understood through ideas, core theme, through creating and integrating programs, independent virtual or physical objects.

Previous deals with optimistic or critical speculation of the object, at present AI becomes the vital icon of IT to tackle difficulties of IT tasks, and in economics and management too. This article focus on marketing view of AIA and its work in digital Marketing World.

\section{AIM AND TASKS}

This article aims focus the horizons and issues, which is going to be faced due to future implemetation digital and economic world with new entrants in digital markets mentioned previously by AIA. Objectives are like primary tasks, human ought to come across in short span of time.

Primary task:

- To inform the significance, form of marketing and examination of AIA, like a tool to exchange economy.

\section{Secondary task:}

- Explaining the norms of autonomous AIA as an active participants in market of this digital world.

\section{Tertiary task:}

- The core theme of dicussion is descriped in the growth of management science. And its features and relations in this paradigm.

Pupil in AI, divided as sub-parts that fails in effective interaction. These rise up with various approach with ideas for AIA, besides with new means of technology. AI involves with activities like learning, remaining, planning, communication, perceiving with mobility and manipulating the objects.

Approaches, prerequisites, with concepts that stimulate to solve hurdles and tasks in report are as follows: $\checkmark$ Development of AI theory [1] $\checkmark$ Improvement in informatics like science, the Internet and the digital environment; $\checkmark$ Idea of "Internet of Things"; $\checkmark$ Idea of "Internet of Everything"; $\checkmark$ Implementation in digital marketing, the conception marketing 5.0;[3] $\checkmark$ Implementation in all over blockchain technology with application in digital marketing. 


\section{THE THEORY}

Discussion of overall view of AIA in the new humanity with developed physical or virtual, digital marketing. Primarily, it starts with individual interaction, then moves to transaction with other AIAs. And its development focuses on the way of transformation from production to economy of digital marketing.

\section{INTELLIGENT AGENTS}

Intelligent agent, an agent with rational thinking, it involves the act of machinery object as like a human with rational mind in the issues of surrounding through sensors and proceed with actuators to get it goal. And this ideas are developed by theoreticians of AI Stuart Russell and Peter Norvig. [1]

Literaly intelligent agents are mentioned as:

- AI agents with abstract nature is opposed and examples are:

- autonomous intelligent objects points at its expression of autonomous nature and its capacity to develop its experience of customized knowledge to obtain their ability can to balance the inaccuracy of past knowledge.

Specific examples of broad definition includes:

$>$ Computer programs as well as software agents, $>$ Robots, machines and devices,

Displaying goals on the basis of behavior:

$>$ Customised

Percept sequences, knowledge, environment.

$>$ The power of agent to perform.

$>$ Assessed with performance in the basis of behavior sets out its day for achievement. AIAs pierces into our routine life, from subway vending machines to unmanned vehicles. Business deals in the digitalized world gets automated, system with AI serves a lot, and time matters in the part of market and marketers to be in a direction to AIA. There are various development in our time, it is quick possible for a vehicle with AI to enter workshop to make its first payment. Even it may arise a question, will it possible for AIA to stand alone and prove itself in market, but it will. Presently, these AIA provides different assets to its holders. By the way, the purchase of these as an independent thing needs recognized AIA status in the commercialfield and civil law in its required limits. Then these rights ought to be standardize and registered by authorities of the nation. Attaining the needed rights AIA can carry out legal economic transactions, and can be a actual participant in economic system and status.

Presently, numerous purchase of AIA as server, which provide crypto-data in virtual markets on it basic qualities and investments. Its no longer to see a vehicle to enter in a taxi for the purpose of collecting revenue, especially a vehicle with its artificial intelligence. Accordingly, taxi companies, despite of using human as drivers for car, its easy for them to use unmanned vehicles for directing passengers or goods in familiarized and populated area.

This can be tackled like practice in Janex Taxi in the Russian Federation and Uber. From the above mentioned thing we can have a clear idea of these things yet it leads to estimate minimum a couple of major parts of the AIA market - like holding households like persons and businesses of legal entities as another. And it is obviously these are seen as varieties of players under the ownership of existing centers shops, restaurants, petrol stations, metro stations instead of human; under the base idea of Internet of Things and Internet of everything.

From my view, AIA's marketing can be explained as automatic participant with artificial intelligence in market whoexamine and analyze facts of the external environment, and with the capacity to make own decision by its self for a transaction to reach its predefined strategy. With its majestic appearance it greatly enchants and flourishes even explores the environment of digitalized world at the same time it also pre-warns the upcoming revolution in techniques with emerging marketing techniques.

\section{CHARACTERSTICS FEATURES OF THE CONCEPT MARKETING 6.0}

- Developing all sites with human but with the help of artificial intelligence.

- To increasee the growth of AIA in market through several services.

- AIA are prominently situated in the service areas.

- AIA is used for easy generation stable income for its owners.

\section{Terms of realization of the concept of Marketing 6.0}

1. Forms of commissions in AIA, based on economy can be obtained by developing digital environment to know the idea of Marketing 4.0 along integrated core theme of both the Internet of Things and Everything.

2. The presence of needed technical infrastructure on a given territory, mentioned as interner of furious links with full of its coverage.

3. Standard recognition of AIA, is noted in economic turnover.

Forms of Marketing relationships realized throughMarketing 6.0. In addition to that relationships of Marketing 1.0, 2.0 and $3.0,[2] 4.0,5.0$ of the markets such as is mentioned as:

TABLE I.

TYPES OF MARKET RALTIONSHIPS AFTER THE INTRODUCTION OF THE CONCEPT OF MARKETING 6.0

\begin{tabular}{|c|c|c|c|c|c|c|c|c|c|}
\hline [1] & & [2] & Business & [3] & Customer & [4] & Government & [5] & AIS \\
\hline [6] & Business & [7] & $\begin{array}{l}\mathrm{b} 2 \mathrm{~b} \\
\mathrm{n}\end{array}$ & [8] & $\begin{array}{c}\mathrm{c} 2 \mathrm{~b} \\
\mathrm{n}\end{array}$ & [9] & b2g & [10] & b2a \\
\hline [11] & Customer & [12] & $\mathrm{c} 2 \mathrm{~b}$ & [13] & $\mathrm{c} 2 \mathrm{c}$ & [14] & c2g & [15] & c2a \\
\hline [16] & Government & {$[17]$} & $\mathrm{g} 2 \mathrm{~b}$ & [18] & g2c & [19] & g2g & [20] & g2a \\
\hline [21] & AIS & [22] & $\mathrm{a} 2 \mathrm{~b}$ & [23] & $\mathrm{a} 2 \mathrm{c}$ & [24] & a2g & [25] & $\mathrm{a} 2 \mathrm{a}$ \\
\hline
\end{tabular}


It is clear from the information given in Table 1, in addition to our familiar relationships, we have four more possible transactions on the market, such as:

- b2a discuss a union among business organization and AIA; - c2a dicuss the connection among both customer and AIA; - g2a explains the link among government organization and AIA;

a2a a transaction between two AIAs. At the same way, as mention above, we can claim too soon we can visualize a smart refrigerator will take down orders from retail outlets, physically or digitally entirely AIA.

The acceptance of unmanned, automatic AIA as full worker in this digitalized realm for ataining the status of both physical and legal entity with assured effect is a aim of this work. In this work the focus is to point the problem and define it.

Automated AIAs are rooted deeply in our day-to-day life, begins with vending machines, extented till unmanned metro vehicles.

In this digital environment, everything is getting automated, it shows the technical development besides system and integrated programs with AI becomes the significant part of our life and it is a time when every part of market focus and works on the basis of AIA. As mentioned earlier, we should aware of the fact, we are nearing the point of getting an unnamed vehicle with AIA, for car service to get its first payment.

The improvement in this payment will be an enrichment in commercial law for predicting the required AIA status in the domain of commercial and civil law, as an individual or a subject with rights.

The process of acquisition of these rights ought to be institutionalized and gained by the respective national legislations. It is possible only after gaining the necessary powers, AIA can able to carry out economic transactions,inorder to be a complete participants in certain economic systems.

\section{Merits of AI for Digital Marketers}

- AIA can hyper-personalize the experience of dealers by verifying their profiles.

- AIA increases the production of particular types and formats in content.

- AI-powered software can decide the creation as well as the distribution of contents.

- AIA can create huge quantities of data and predict it fine on the basis of emerging patterns from it.

- AIA can foresee the behaviour of customer and identify and nurture the most valuable leads.

\section{AI and Digital Marketing}

The present trends have stepping strong in digital marketing, is highly vital, while developing a fine strategy in our business. As major world's population is connected to the network, it is important to know, how contact or convince the customer as their products are the best.
By trapping the attention of the customers one can step on the way of success, so development in their business should update often. Artificial intelligence enhances the communication with consumer, more than a direct way. Thought it is tough to understand, by anallysing the nature of users to capture what they really want and need.

$\mathrm{AI}$ and its application marketing of companies yield endless yielding. Among them, the following notable:

- By comparing with other campaigns, internet campaigns economical. Each can develop their business by a campaign with less investment that will give huge positive results and publicity.

- By considering the outcome when the campaign is underway, we can edit or provide effective advertisement that we need to give. This will pay way to better result.

- Through the analysis of environment, it is possible to find out why customers are fond of that item, service to gain better information over the rest.

- Customer service, it is ought to know that the customer is new to the business and therefore it is easy to satisfy them. It is applied to marketing campaigns accelerates and solves everything that ends as an effective problem for the customer. Through Call Centre Software, telephony solutions also provided. Efficient company with effectiveness and quality customer service.

- New products or services can be provided through studies and valid information from the clients.

\section{AI Strategies in Marketing Campaigns}

It is needed to analyse the strategies, which are to carry out campaigns that will improve your business with high profit and quality. To achieve this, it is needed to gather the models which strengthen the commercial strategy, like prediction models.

\section{Different prediction models:}

- A high visual content, that will promote the attention of the users with images, videos, gif, etc.

- As a tool, international phone numbers will allows statistical reports of campaigns. They are numbers which will not need investing in equipment or installing.

- Client's datum are stored in cookies and to be personalizing as per the needs of users.

\section{Artificial Intelligence dominates the world of marketing}

Artificial Intelligence and its significances has found in marketing, with the connection of effort and time for the past tasks. Now, marketers can get involve themselves to managing activities which did not give them time in the past.

1. Market Analysis

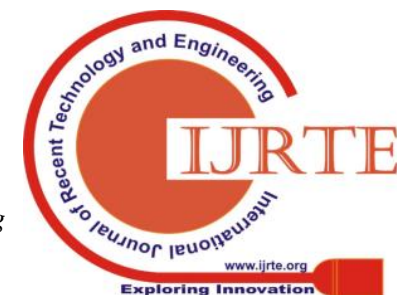


2. Generate content

3. Changes in the way of searching for information

4. Chatbot

\section{Role of Artificial Intelligence in Future of Marketing}

The Marketing field has earned a lot by AI. It involves huge pre-planning, decision making, dealing with volatile things, and right implementation. AI proves it as the best decision making system as it motivates the decision maker with inputs most required to reach a conclusion viz. predicting it through forecasts, analysing the data and trends, with up-to-date information, reducing information load, etc. It has a vital role in the future of marketing.

Examples of artificial intelligence in marketing

Artificial intelligence Applications and machine learning are developing vital of thing of various sector, which includes marketing too.

1. Product/content recommendations

2. Search engines

3. Sales forecasting

4. Data filtering \& analysis

5. Product pricing

6. Chatbots\& conversational AI

7. Speech recognition

8. Visual search \& image recognition

9. Social listening \& sentiment analysis

10. Product categorisation

11. Programmatic ad targeting

12. Predictive analytics

13. Audience targeting \& segmentation

14. Copywriting

15. Computer vision \& augmented reality

\section{V.CONCLUSION}

In this article focus is shed on the introduction, characteristics, trends, applications and benefits of Marketing with the usage of AI. On the basis of review of the literature and from the view of experts, the subject of artificial intelligence and its applications on the marketing, we gain the theory that it is too near to visualize the upcomings, wher the users of digital economy enjoys AIA like goods of investment, which has the duality role in the digitalized world and marketing economy, to be a mean of production and, to be a agent of representation, agents of marketing, digital marketing which can change their level of profit through its rational behavior by mean of increasing or decreasing it.

\section{REFERENCES}

[1] Russell, Stuart J ? ??. Artificial Intelligence: A ModernApproach. 2nd. Upper Saddle River, New Jersey, PrenticeHall, 2003

[2] Philip Kotler, HermawanKartajaya, Marketing 3.0: From Products to Customers to the Human Spirit, 2010

[3] Philip Kotler, HermawanKartajaya, Marketing 4.0: Moving from Traditional to Digital, 2016

[4] A. K. Kirtis and F. Karahan, "To Be or Not to Be in Social Media Arenaas the Most Cost-Efficient Marketing Strategy after the GlobalRecession," Procedia - Social and Behavioral Sciences, vol. 24 pp.260-268, 2011.
[5] Sridevi and Senthil Kumar, "EmergingTrends in Online Marketing", in ICTACTJournal on Management Studies, February2015, Vol.01, p 34-38.

[6] Anitha, "Consumer Preference towards Online Retailing", in ICTACT Journal onmanagement studies, May 2015, Vol.01, Issue 02, p 74-80

[7] Philip Kotler, "Marketing Management",11th Edition. Prentice Hall: New Delhi,2003.

[8] Roman G. Hiebing and Scott W. Cooper,"The Successful Marketing Plan". TataMcGraw-Hill Publishing CompanyLimited: New Delhi, 2007.

\section{INTERNET SOURCES}

[1] '2016 Digital Marketing Trends', Availableat http://www.smartinsights.com/tag/2016-digital-marketing-trends.'Tre nds Driving the Future of Marketing',Available at www.forbes.com.

[2] 'Digital Marketing', Available athttp://bit.ly/smarttransformation.com.

[3] Online Strategies accessed in LinkedInAvailable inhttp://www.linkedstrategies.com /aboutlinkedin/

[4] 'The Future of Digital Marketing',Available at www. inc.com. 